\title{
Underground Cable Fault Detection and Prevention Using Blynk
}

\author{
Halith Hamja K.J ${ }^{1 *}$, Illavarason $\mathrm{P}^{2}$, Sridevi Ponmalar $\mathrm{P}^{3}$ \\ ${ }^{1}$ PG Scholar, ${ }^{2}$ Assistant Professor, ${ }^{3}$ Professor \\ ${ }^{1,2}$ Department of Computer Science and Applications, ${ }^{3}$ Department of Computer Science and \\ Engineering, \\ ${ }^{1,2}$ Periyar Maniammai Institute of Science \& Technology, Periyar Nagar, Vallam-613 403, Thanjavur. \\ ${ }^{3}$ New Prince Shri Bhavani College of Engineering and Technology, Chennai. \\ ${ }^{1}$ kjhamja77@gmail.com, ${ }^{2}$ illavarason@pmu.edu, ${ }^{3}$ srideviponmalar@gmail.com
}

\begin{abstract}
In India most of the metropolitan cities using underground surface for transferring the EB and BSNL lines. That's why this project is very needed, we supposed to reduce the human power and loss of energy. In this we attach some sensors to the cable with microcontroller in underground and that sensor shows the fault location accurately, by this we can reduce the time and human power for searching for fault location. And more than that we can even prevent the cable from getting fault. the process if any fault occurs that we can see the accurate location by the sensor, that gives the location to microcontroller and the controller sends the location to the system which was connected in the wireless communication with mobile. We can prevent the cable from getting fault by find out how the cable getting fault and then we attach sensors for monitor the types of fault.
\end{abstract}

Keywords: Fiber optic cable, microcontroller, nodemcu.

\section{Introduction}

That fiber optic cable is very useful in sending the data from one place to other places in the format of light. That almost in foreign countries implemented the underground surface to transfer the current supplies and phone lines in the underground to safe and secure and that they installed and upgraded the wires to fiber optic cable for the transmission because it is very safe and it is very fast in transmitting the data.

The Objective of the proposed research includes:

- To prevent the cable from getting fault by using flex, piezoelectric, moisture sensors.

- To analyze the fault in underground cable we use LDR sensor.

- To analyze fault by loss of signal in the underground cable.

- The mobile is connected with microcontroller to show the location of prevention needed and fault location also.

- The fault location sends to the mobile device and that location appears on the Blynk software. 


\section{Introduction to IOT}

That Internet of Things(IoT) which means that connecting the hardware and software for upgrading the technologies. IoT that it is done by sensors and microcontroller. IoT is the basic of AI. It is very useful in creating the projects for social awareness and use this to improve agriculture and we can make all the factories to automatic for avoiding the human loss and avoid human from getting diseases.

\section{Microcontroller}

Microcontroller is like a tiny of computer and it was like a processor, because it has its own configuration and we can use this microcontroller for these kind of projects. It takes instruction by code and it finish the task. There are many microcontrollers like arduino, PIC, NodeMCU etc.

\section{$4 \quad$ NodeMCU}

For this project used this nodeMCU it is small in size and it has inbuilt wifi module, that's why it is called as wifi module. We can instruct the task to this microcontroller and we can even connect this nodeMCU to sensors with wireless connection and we can use this controller to send the information to the system or any other device by wireless communication and we can even use GSM communication by this microcontroller.

\section{$5 \quad$ Light Sensor}

LDR (light dependent resistor) it is called as light sensor, because it detects the light. We use this sensor to detect the fault in the cable in the underground surface, we use fiber optic cable, so the data is in the format of light that's why we use this sensor. Fig 1 represents the LDR - Light Dependent Resistor

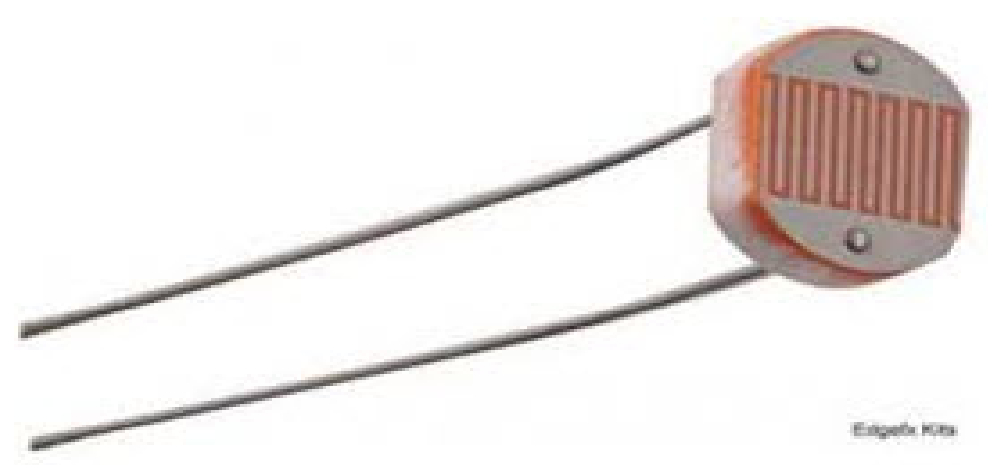


Fig. 1. LDR - Light Dependent Resistor

\section{Soil moisture sensor}

Moisture sensor is used to detect the level of water content in the soil and it is very useful in the agricultural projects. We use this sensor to detect the water level in the soil. We use this to check the water content is high for a certain period of time means it can affect the cable so we use moisture sensor to prevent the cable. Fig 2 represents the Soil moisture sensor.

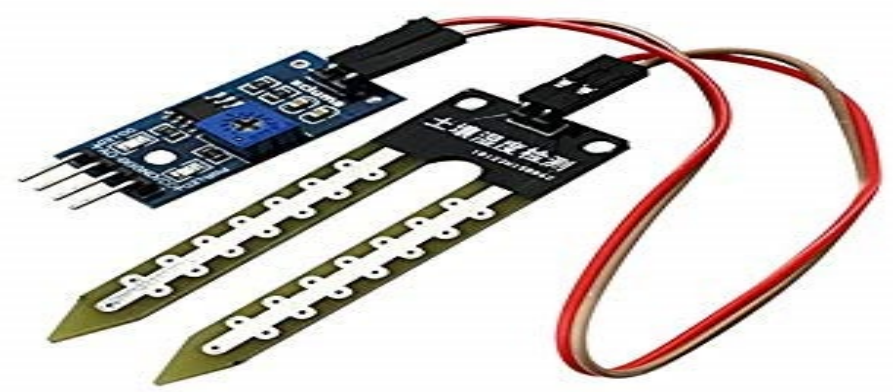

Fig. 2. LDR - Soil moisture sensor

\section{$6 \quad$ Flex sensor}

Flex sensor is also called a bend sensor, because this is used to calculate the bend of some object by the values with the help of angle that the sensor bend. We use this sensor to calculate the cable bend in the underground surface. There are two types of flex or bend sensor that was divided by the size of the sensor, that is 2.2 inch and 4.5 -inch flex sensor. That image below is 2.2-inch flex sensor. Fig 3 represents the Flex sensor. 


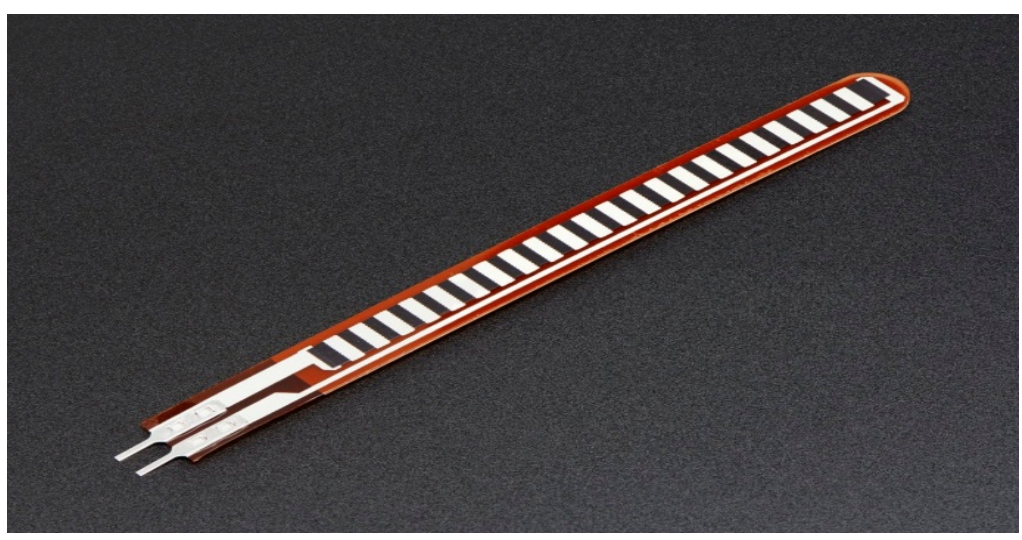

Fig. 3. Flex sensor

\section{$7 \quad$ Piezoelectric sensor}

Piezoelectric sensor is used to detecting the pressure of any object, so it is also called as piezo disk. we can use this sensor as input and output because this is the component which is used in buzzer and speakers as output. We can use this disk to sense the pressure and we can use this disk for making sound for output also. Fig 4 represents the Piezoelectric sensor.

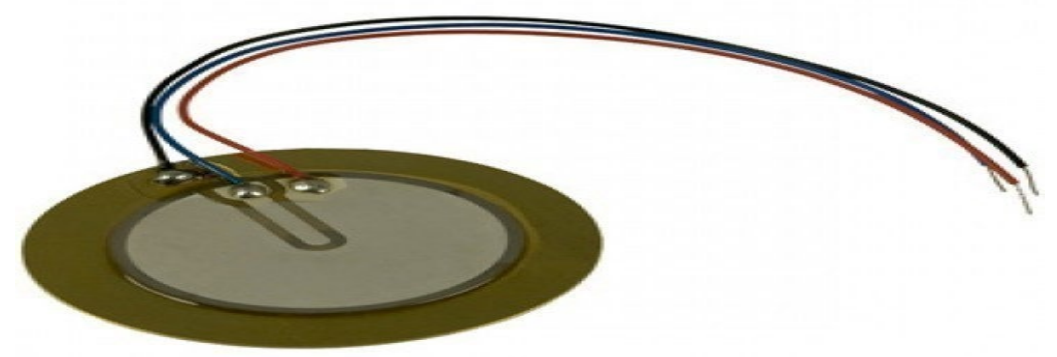

Fig. 4. Piezoelectric sensor

\section{Literature survey}

Table 1 represents the Literature Survey on Underground Cable Fault Detection and Prevention Using Blynk.

Table 1. Literature Survey on Underground Cable Fault Detection and Prevention Using Blynk 


\begin{tabular}{|c|c|c|c|}
\hline $\begin{array}{l}\text { Author \& } \\
\text { year }\end{array}$ & $\begin{array}{l}\text { Published } \\
\text { Year }\end{array}$ & Outcome & Research findings \\
\hline $\begin{array}{l}\text { Ansa } \\
\text { Sebastian et } \\
\text { al., [1] }\end{array}$ & Mar 2018 & $\begin{array}{l}\text { IoT based Underground } \\
\text { Cable Line Fault Detection. }\end{array}$ & $\begin{array}{l}\text { Author used to create a voltage when a fault } \\
\text { occurs using resistor network, they used IOT } \\
\text { gecko for smart notification. }\end{array}$ \\
\hline $\begin{array}{l}\text { Kiran } \\
\text { Wadekar et } \\
\text { al, [2] }\end{array}$ & 2017 & $\begin{array}{l}\text { IoT Underground Cable } \\
\text { Fault Detection }\end{array}$ & $\begin{array}{l}\text { Author used ohms law and they find the fault } \\
\text { location by variation of voltage drops in } \\
\text { series resistor. }\end{array}$ \\
\hline $\begin{array}{l}\text { N. } \\
\text { Sampathraja } \\
\text { et al., [3] }\end{array}$ & Aug, 2017 & $\begin{array}{l}\text { IoT based Underground } \\
\text { Cable Fault Detection }\end{array}$ & $\begin{array}{l}\text { Author used ohms' law. they find the fault } \\
\text { by voltage changes in the cable }\end{array}$ \\
\hline $\begin{array}{l}\text { Arjun Nicha } \\
\text { et al., [4] }\end{array}$ & $\begin{array}{l}\text { April } \\
2016\end{array}$ & 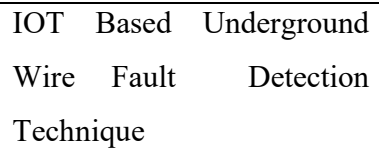 & $\begin{array}{l}\text { Author finding the faults by the variation of } \\
\text { the voltage by using series resistor }\end{array}$ \\
\hline $\begin{array}{l}\text { HennaSam. } \\
\text { E.J et al., } \\
{[5]}\end{array}$ & $\begin{array}{l}\text { April- } \\
\text { June } 2018\end{array}$ & $\begin{array}{l}\text { Underground Cable Fault } \\
\text { Detection Using IOT }\end{array}$ & $\begin{array}{l}\text { Author used ohms' law. If any fault occurs } \\
\text { the voltage changes in series resistor }\end{array}$ \\
\hline $\begin{array}{l}\text { Sravani, et } \\
\text { al., [6] }\end{array}$ & $\begin{array}{l}\text { April } \\
2018\end{array}$ & $\begin{array}{l}\text { Implementation of IOT to } \\
\text { Detect and Display } \\
\text { Underground Cable Fault }\end{array}$ & $\begin{array}{l}\text { Author converting analog to digital and then } \\
\text { they convert digital to resistance value that } \\
\text { value is fault location }\end{array}$ \\
\hline $\begin{array}{l}\text { RaghulMan } \\
\text { singh, et al., } \\
{[7]}\end{array}$ & $\begin{array}{l}\text { April } \\
2017\end{array}$ & $\begin{array}{l}\text { Underground Cable Fault } \\
\text { Detection using Raspberry } \\
\text { Pi and Arduino }\end{array}$ & $\begin{array}{l}\text { Author used CT theory. They used current } \\
\text { varies CT to find the variation of voltage }\end{array}$ \\
\hline
\end{tabular}


The Internet of Things has a wide scope of applications and can be effectively actualized in areas, for example, the healthcare sector, retail business, travel and tourism, hypermarkets, event management, the manufacturing sector, environmental systems, logistic systems, hotels and eateries and significantly more [8]. This expansive range of utilization areas delineates the IoT as assuming an imperative job in the smooth working of society. In the 2005 report of the International Communication Union, the IoT was proposed as a collaboration of computing and sensor-based technologies, for example, sensors, remote networks, installed systems, object identifiers and nanotechnologies. This mix empowers the articles to be labeled, detected and controlled over the networks.

The IoT is viewed as a mix of technologies meant to give collaboration and communication among connected gadgets. A few enterprise systems, for example, healthcare, the industrial sector and so on, in view of IoT applications have additionally been created. Creating nations additionally appear to be definitely inspired by the IoT. The previous Chinese President inaugurated a national IOT research focus in 2009 and conveyed a discourse about the requirement for cutting edge research and advancement in the IoT field.

\section{$9 \quad$ Proposed Architecture diagram}

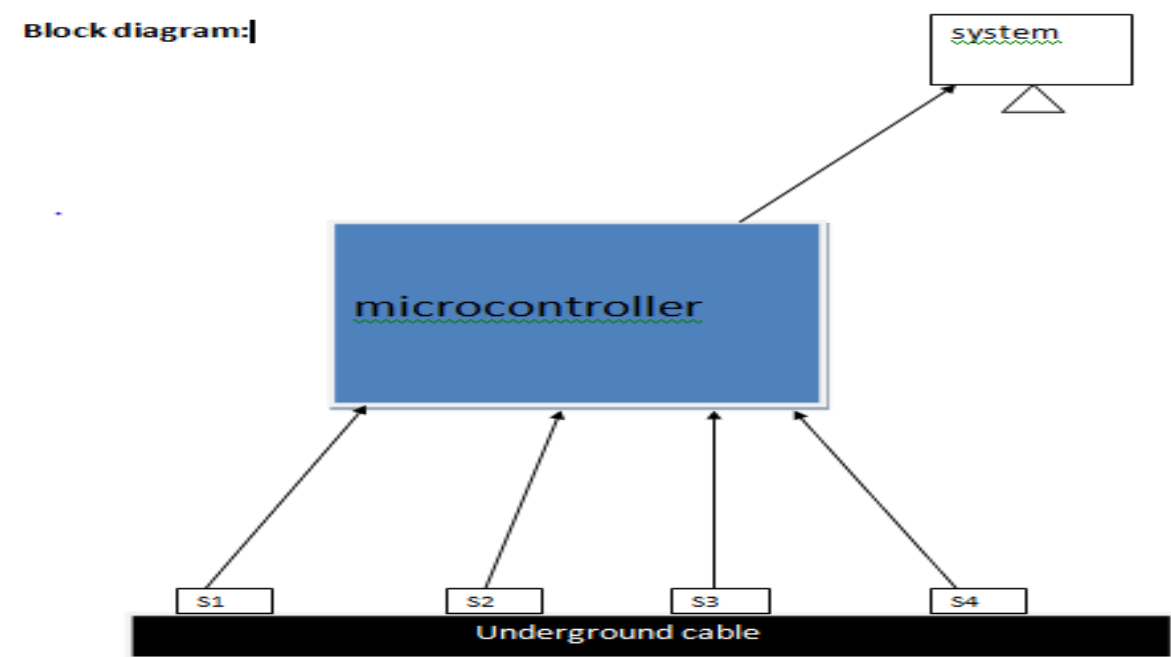

Fig. 5. Block Diagram of Proposed Methodology

\section{Methodology}

The Methodology of Proposed Work are:

- Get a foam board attach the cable in the board. 
- Attach the sensors in the cable and attach the microcontroller in the board.

- Connect the microcontroller and sensors with the jumper wires.

- Connect the microcontroller with the system connected over a wireless network.

- Upload the instruction to the microcontroller.

- Cut the cable to get the fault location, bend, press and split water in the sensor for preventing it sends the prevention location where the cable going to get fault in future.

\section{Implementation}

The Proposed Implementation Methodology are shown in Fig 6.

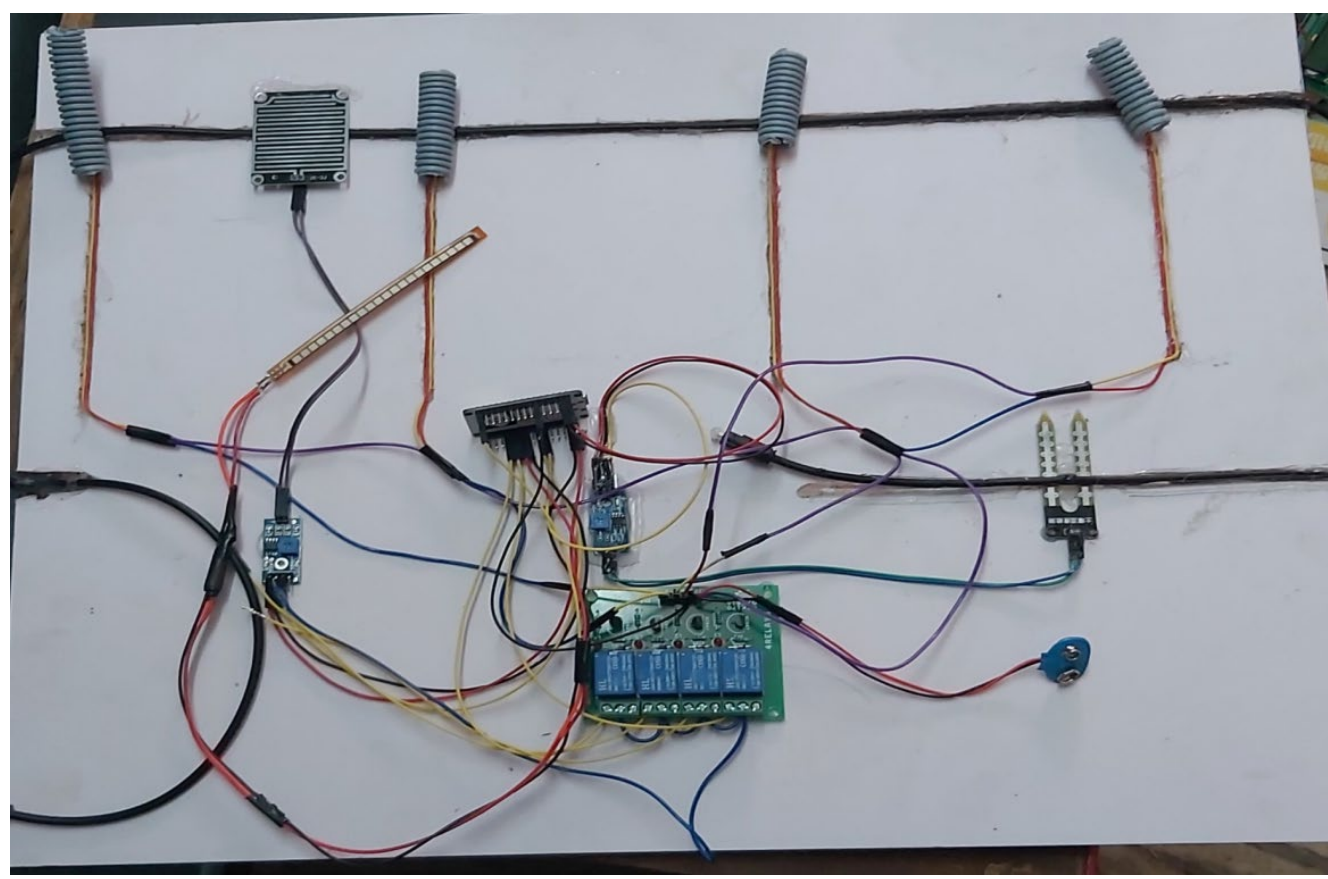

Fig. 6. Block Diagram of Proposed Methodology

\section{Result \& Discussions}

Table 2 represents the Proposed Systems Results Obtained by applying various method for fault detection and prevention. Fig 7 represents the Result analysis graph obtained from various methodology applied. Fig 8 represents the Result Screenshot for Cable Fault Accuracy. 
Table 2.Proposed Systems Results Obtained by applying various method for fault detection and prevention

\begin{tabular}{|l|l|l|}
\hline Applied methodology Name & Methodology process & Accuracy Rate \\
\hline LDR Method & Identifying the fault & $90 \%$ \\
\hline Pressure sensing method & Preventing the cable & $85 \%$ \\
\hline Soil moisture sensing method & Preventing the cable & $90 \%$ \\
\hline Cable Bend sensing method & Preventing the cable & $95 \%$ \\
\hline
\end{tabular}

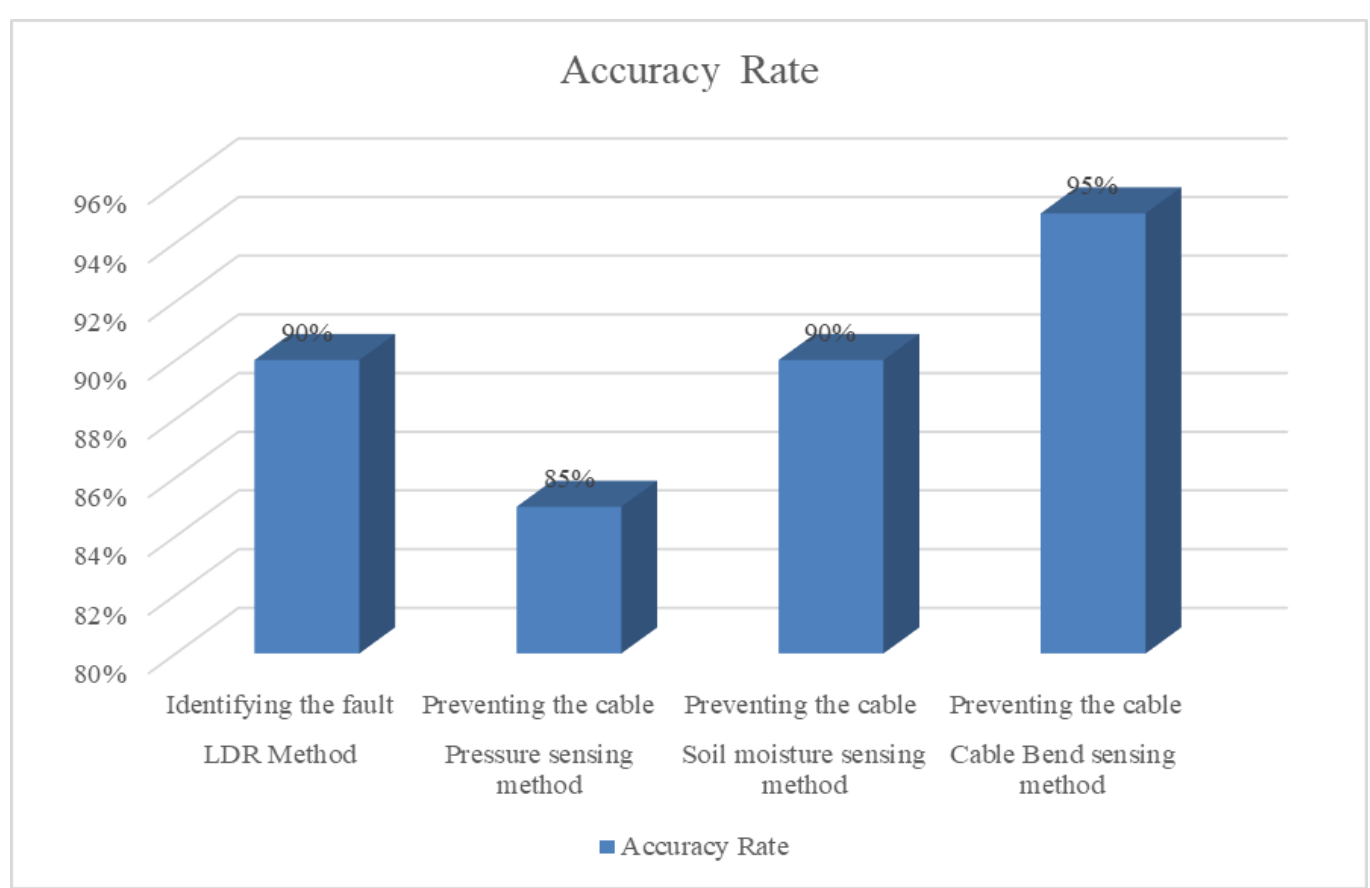

Fig. 7.Result analysis graph obtained from various methodology applied 


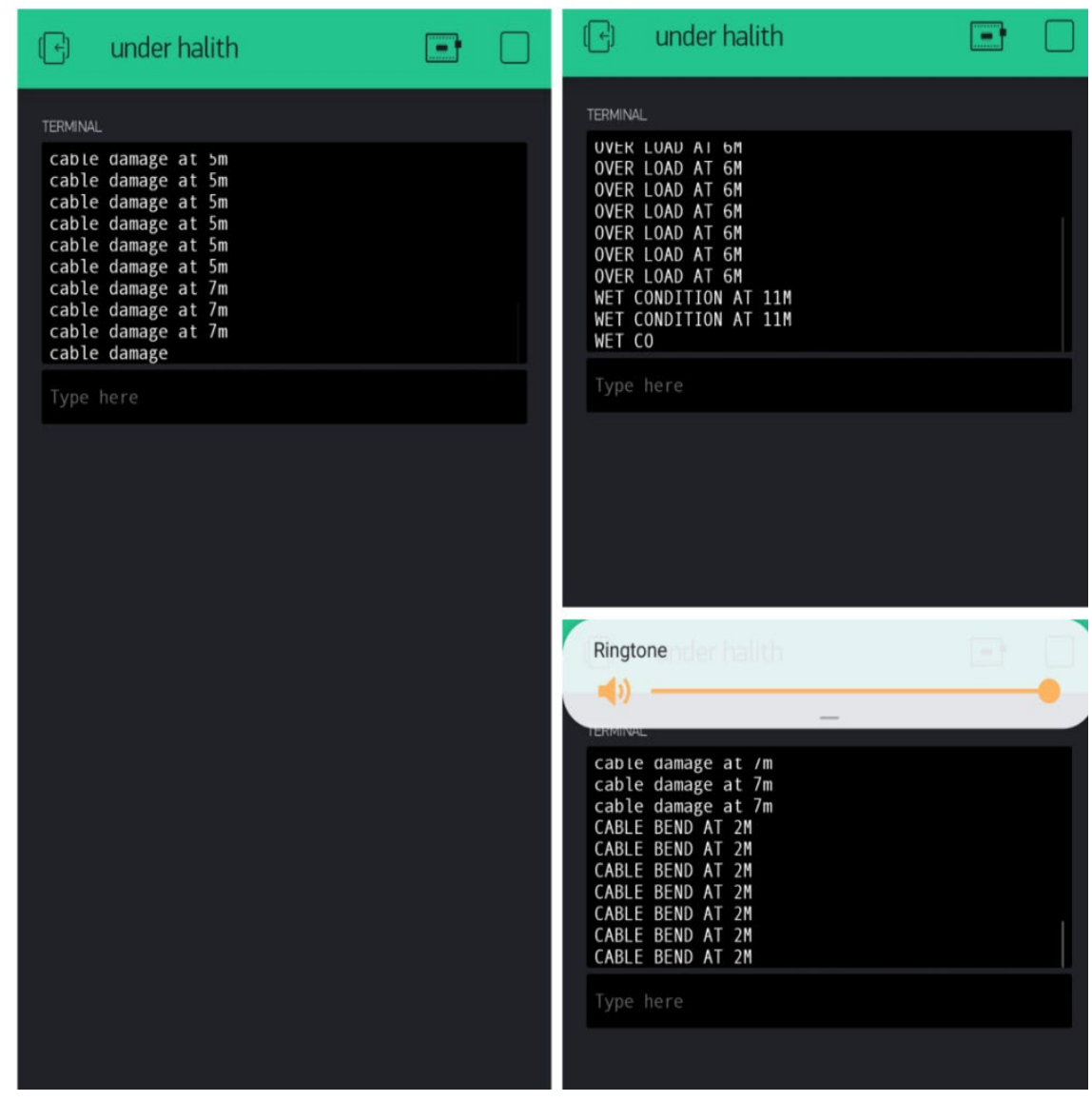

Fig. 8. Result Screenshot for Cable Fault Accuracy

\section{Conclusion and Future scope}

The proposed method embedded the sensors over the fiber optic cable for more accurate results and reduce the cost of the project and create a layer and attach the sensors in the layer and connect the sensors through wireless communication using blynk and getting the data to a permanent mobile device.

\section{References}

[1] Ansa Sebastian, Anu Jacob, Angel Wilson, Ann Rija Paul, Department of Computer Science and Engineering, IoT based underground cable line fault detection, International Research Journal of Engineering and Technology (IRJET) Volume: 05 Issue: 03, Mar-2018

[2] Kiran Wadekar, Vaibhav Borkar, Rahul Ghule, Manish Patel, IoT Underground Cable Fault Detection, Vol-3 Issue-3 2017, IJARIIE-ISSN(O)-2395-4396 
[3] Sampathraja, Ashok Kumar, Kirubalakshmi and Muthumaniyarasi, IoT Based Underground Cable Fault Detector, International Journal of Mechanical Engineering and Technology (IJMET) Volume 8, Issue 8, August 2017

[4] Arjun Nicha, Sudarshan Bhosale, Vaibhav Shirsavade, Yogesh Jadhav, IOT Based Underground Wire Fault Detection Technique, International Journal of Innovative Research in Electrical, Electronics, Instrumentation and Control Engineering, Vol. 4, Issue 4, April 2016

[5] Henna Sam.E, Pavithra.U, Ramakrishnan.P, Riyash Basha and T.M.Sathish kumar, Underground Cable Fault Detection Using IOT, Asian Journal of Applied Science and Technology (AJAST) Volume 2, Issue 2, Pages 737-746, April-June 2018

[6] B.Sravani, K.Sekhar, Sri Jagannatham, Sateesh, Venkateswaramma, Implementation of IOT to Detect and Display Underground Cable Fault, 2017 IJRTI, Volume 2, Issue 3, ISSN: 24563315

[7] R.K.Raghul Mansingh, R.Rajesh, S.Ramasubramani, G.Ramkumar, Underground Cable Fault Detection using Raspberry Pi and Arduino, International Journal of Emerging Technologies in Engineering Research (IJETER) Volume 5, Issue 4, April (2017)

[8] J. Dafni Rose, K. Vijayakumar and S. Sakthivel, "Students' performance analysis system using cumulative predictor algorithm”, Int. J. Reasoning-based Intelligent Systems, Vol. 11, No. 2, 2019. 